hand to mouth, as the Russian academy. As a stopgap, that is probably necessary, but outside help will be essential if able people are to remain productive (or even where they are). But the structure will not suffice for the long run if the Russian government endorses even a small part of the old Marxist rhetoric about the importance of science in the modern state. Radical upheaval will be required.

Here is why, and how. The present system in which a network of research institutes (now truncated by the departure of the Ukraine) is supported and managed directly by an academy embodies an intolerable conflict of interest. Especially in such rough times, the interests of the academy are indistinguishable from those of the directors of its institutes, traditionally personal fiefdoms in which the power of personal patronage, even if moderated by the notion that the institutes will be collectives, will now be greater than ever. These are hardly the circumstances in which basic research can flourish, nor will they help to create a research enterprise of the kind that a would-be modern state such as Russia needs. The academy's complacent assumption that only its own institutes are worthwhile is at once mistaken (many of its institutes are second-rate) and a recipe for the indulgence of self-interest. (The old academy's attempts to set up a system of competitive research grants might have been more successful if its own payroll pensioners had been less influential in its councils.) When this transitional year is over, it should withdraw from the direct management of research.

There is plenty of other work to be done. What, for example, is to happen to the universities which, despite the efforts of Gorbachev's able minister Yagodin, are still largely cast in their Stalinist mould, itself a means of keeping students away from knowledge judged irrelevant to their immediate needs as well as from the traditional subversiveness of teachers? An academy with the national interest (Russia's now) at heart could have a decisive influence on the overdue restructuring of the universities - and on the encouragement of research therein.

There is a similar need in the new republics' reconstruction of the apparatus of industrial research. During 75 years of central planning, production ministries have maintained research institutes to serve the needs of their own production plants, while the Soviet academy's institutes were regarded as a source of radical innovations that might, after negotiation within a labyrinthine bureaucracy, be scheduled for production at a factory whose managers might not previously have known what was in the wind.

There could hardly have been a mechanism for what is called technology transfer less suitable for matching the performance of new products to market needs. The notion that academy institutes, functioning as collectives, may now make deals with production enterprises may help a little, but that random process will do little to equip Russia or any of the other republics with the skills in research and development they will eventually need. What, in the meantime, can be done to keep alive and to improve a hard core of industrial research and development? The Russian academy could more easily bend its mind to that important issue if it were freed from the anxiety of keeping its own institutes in being.

To blame Gorbachev for not having resolved these problems while still in office would be unfair. He had other things on his mind. But it is a fact that nothing much was done in his time to change a structure of research so cumbersome and unsuited to its declared purposes that it is almost miraculous that so much talent has survived in spite of it. With all the social upheavals now in prospect, the decades ahead will not be so lucky unless reform comes soon.

\section{Opening for US science}

US scientific organizations want (and need) to find ways to help colleagues in the former Soviet Union.

THE crisis in the republics of what was the Soviet Union presents a special challenge to scientists in Western nations who want to see science not only survive but also improve as an enterprise during the coming years. The new Russian Republic, home to the majority of the most able Soviet scientists, is of special concern, particularly in the light of reports that as many as half of Russia's most cited scientists have left the country. What are the immediate needs? What can be done?

Although the organizational structure of Russian science is in disarray (former Soviet colleagues are no longer in positions of authority or lack resources), various groups of US scientists are trying to maintain contact. Recently, the US National Academy of Sciences (NAS) sent a delegation from its committee on dual-use technologies to talk about future industries. Concern about the fact that Russian scientists (like those in the Ukraine and elsewhere) have no currency to purchase essential reagents, spare parts and the like, has led to conversations between the NAS and the US government, as well as the Royal Society in Britain, about ways to help. But no decisions have been reached.

On 10 January, a group representing wealthy US foundations, including the Rockefeller, Carnegie, MacArthur and Ford Foundations, will leave for Moscow on an exploratory mission. With the ruble virtually worthless, contributions of even a few millions of dollars could have a major impact on the professional lives of Soviet scientists.

The American Academy of Arts and Sciences, whose headquarters are in Boston, is also thinking about ways to help. One plan under consideration is to form a clearing house for information on grants and potential collaborations. Provisions in certain US research grants, for instance, permit as much as 5 per cent of funds to be allocated to work with scientists from other countries.

These and other ideas for helping scientists in the new republics during this period of hard transition are in a nascent stage. It is essential that as many as possible come to fruition very soon. 